\title{
Effect of temperature on some biological parameters of an Iranian population of the Rose Aphid, Macrosiphum rosae (Hemiptera: Aphididae)
}

\author{
MOHSEN MEHRPARVAR ${ }^{1}$ and BIJAN HATAMI ${ }^{2}$ \\ ${ }^{1}$ Department of Ecology, International Center for Science, High Technology \& Environmental Sciences, \\ Kerman 7631133131, Iran; e-mail: mehrparvar@icst.ac.ir \\ ${ }^{2}$ Department of Plant Protection, College of Agriculture, Isfahan University of Technology, \\ Isfahan 8415683111, Iran; e-mail: bhatami@cc.iut.ac.ir
}

Key words. Aphididae, Macrosiphum rosae, rose aphid, geographic population, Iran, development, survival, fecundity, biology, developmental threshold, degree-day

\begin{abstract}
The rose aphid, Macrosiphum rosae, living on rose var. Black Magic, was reared in the laboratory at four constant temperatures $15,18,22$ and $25 \pm 1{ }^{\circ} \mathrm{C}, 75 \pm 5 \%$ R.H. and $14 \mathrm{~L}: 10 \mathrm{D}$. Parameters investigated included developmental rate, survival, prereproductive delay and fecundity. The rate of nymphal development $(0.17)$ was greatest at $22^{\circ} \mathrm{C}$. The longest developmental time (12.33 days) was recorded at $15^{\circ} \mathrm{C}$. The generation time was longest and shortest at $15^{\circ} \mathrm{C}$ and $22^{\circ} \mathrm{C}$ respectively. The lower developmental threshold was calculated to be $9.05^{\circ} \mathrm{C}$. Based on this, the degree-day requirement from birth to adulthood was found to be $77.5 \mathrm{dd}$. The pre-reproductive delay also decreased markedly with increase in temperature from $15^{\circ} \mathrm{C}$ to $22^{\circ} \mathrm{C}$. The longest lifespan of apterous females $(12.38 \mathrm{~d})$ was observed at $15^{\circ} \mathrm{C}$, whereas the shortest $(8.06 \mathrm{~d})$ was at $25^{\circ} \mathrm{C}$. The mean adult longevity declined with increase in temperature from $15^{\circ} \mathrm{C}$ to $25^{\circ} \mathrm{C}$. The fecundity of females (progeny/female) increased from 11.38 to 28.88 with increase in temperature from $15^{\circ} \mathrm{C}$ to $22^{\circ} \mathrm{C}$ but then decreased to 8.38 as the temperature increased from $22^{\circ} \mathrm{C}$ to $25^{\circ} \mathrm{C}$. The largest (0.311) and smallest $(0.113) \mathrm{r}_{\mathrm{m}}$ occurred at $22^{\circ} \mathrm{C}$ and $15^{\circ} \mathrm{C}$ respectively. All of the parameters of the M. rosae life cycle at the four temperatures tested were optimum at $22^{\circ} \mathrm{C}$. This Iranian population of M. rosae can develop at lower temperatures than an Australian population.
\end{abstract}

\section{INTRODUCTION}

The rose aphid, Macrosiphum rosae (Linnaeus, 1758) is one of the most important pests on roses, with a worldwide distribution (Heie, 1994; Blackman \& Eastop, 2000). It is a significant pest of rose crops and can become very abundant on roses thus reducing their decorative value. In the case of a high infestation, the aphid causes significant damage, e.g. bent stems, weak foliage and early leaf fall. The most significant damage is to the inflorescences, especially at bud burst (Jaskiewicz, 1997). M. rosae is probably a native species of Eurasia (Maelzer, 1977) that feeds mainly on the young leaves and developing flower buds. The honeydew excreted by the aphid promotes the growth of sooty mould on flowers and surfaces of leaves. All of these factors together cause significant economic damage to rose crops by decreasing their beauty and the value of cut flowers (Alford, 1991). This aphid is a heteroecious holocyclic species in temperate regions but may be completely anholocyclic on roses in warmer climates (Blackman \& Eastop, 2000).

In many areas $M$. rosae is a serious pest of roses, and an understanding of its biology and population dynamics is essential for developing a reliable management strategy. Any effective control of pests requires a precise knowledge of their dynamics as well as the factors, such as temperature, which can influence them. Temperature is an important environmental variable that affects the rate of aphid development, reproduction, mortality, survival and subsequently its population increase (Dixon, 1987). Although aphids are not typically subjected to constant temperature, a controlled laboratory study can provide valuable information about the population dynamics of particular species. A change in temperature, when within the range of the species in question, results in a change in reproductive rate and hence in reproductive timing (Dixon, 1987). In this context, food quality is known also to affect insect reproductive timing.

There are numerous studies on the effect of temperature on aphid development (e.g. Wang \& Tsai, 2000; Collins \& Leather, 2001; Morgan et al., 2001; Satar \& Yokomi, 2002). The biology and main causes of changes in numbers of the rose aphid on cultivated roses were studied in South Australia by Maelzer (1977). He studied the effect of temperature on development of apterous and alate individuals under both laboratory and field conditions. The effect of temperature on the biological parameters of a Turkish population of the rose aphid, originating from a region near to Iran, was studied by Olmez et al. (2003) under laboratory conditions.

This study was designed to investigate the effect of different temperatures on the developmental rate, survival, prereproductive delay and fecundity of $M$. rosae under laboratory conditions in order to provide parameters for forecasting and management systems for Iran and similar areas.

\section{MATERIAL AND METHODS}

The effect of temperature on development and population growth of M. rosae on rose var. Black Magic was studied at four constant temperatures $15,18,22$ and $25 \pm 1{ }^{\circ} \mathrm{C}, 75 \pm 5 \%$ R.H. and $14 \mathrm{~L}: 10 \mathrm{D}$ in an insect-rearing room. Terminal shoots $(25-30 \mathrm{~cm}$ length) of roses were detached and used throughout this study. Freshly cut shoots were placed in 5\% sucrose solution. Shoots were replaced every 3 days. Initially, the aphids were allowed to move between the old and new shoots, but sometimes the aphids were gently stimulated with a needle to withdraw their stylets from the plant and move to new shoots. 
TABLE 1. Mean \pm SE nymphal development time, developmental rate and generation time of $M$. rosae at four constant temperatures. Means in columns with different letters are significantly different from one another $(P<0.01$, GLM) in ANOVA (LSD).

\begin{tabular}{cccc}
\hline Temperature $\left({ }^{\circ} \mathrm{C}\right)$ & Developmental time (Day) & Developmental rate $\left(\right.$ Day $\left.^{-1}\right)$ & Generation time $($ Day) \\
\hline 15 & $12.33 \pm 0.2 \mathrm{a}$ & $0.08 \mathrm{a}$ & $15.89 \pm 0.18 \mathrm{a}$ \\
18 & $9.33 \pm 0.22 \mathrm{~b}$ & $0.11 \mathrm{~b}$ & $11.94 \pm 0.35 \mathrm{~b}$ \\
22 & $5.89 \pm 0.23 \mathrm{c}$ & $0.17 \mathrm{c}$ & $7.28 \pm 0.29 \mathrm{c}$ \\
25 & $6.94 \pm 0.3 \mathrm{~d}$ & $0.14 \mathrm{~d}$ & $8.75 \pm 0.24 \mathrm{~d}$ \\
\hline
\end{tabular}

\section{Aphid source}

Wild Macrosiphum rosae were collected from rose bushes on the campus of the Isfahan University of Technology (IUT), Iran. Aphids were collected as nymphs from un-crowded colonies in order to prevent a reduction in fecundity induced by crowding in the nymphal stages (Maelzer, 1977).

\section{Experimental procedures}

The experiment was conducted using an unbalanced completely randomized design. For each experimental temperature, 10 young apterous adults of the same age were each individually placed on one of 10 shoots. Individual adult aphids were checked every $12 \mathrm{~h}$ in order to determine their pre-reproductive delay, longevity, survivorship and fecundity. The period from when young apterous adults were placed on shoots until the birth of their first offspring was taken as the pre-reproductive time. The time between fourth moult until the death of the adult was recorded as the longevity of adults. The number of offspring born to each female was recorded as fecundity. Then all progeny but one were removed from each replicate. The remaining nymph was transferred individually to a new detached shoot using a paint brush and its nymphal development recorded. The time between birth and final nymphal moult was recorded as the developmental time of the immature stages. The period from when the young apterous adults were placed on the shoots to the fourth moult of their nymphs was recorded as the generation time. The intrinsic rate of increase $\left(r_{m}\right)$ was calculated using Wyatt \& White's formula (1977). This formula is

$$
\mathrm{r}_{\mathrm{m}}=0.738 \frac{\ln M_{d}}{d}
$$

where $M_{d}$ is the number of nymphs produced over a period of time equal to that of the entire pre-reproductive period $(d)$.

Ten aphids were tested at each temperature. Those that reached the adult stage were included in the calculations of nymphal development time. Individual adults that escaped or died were excluded from reproduction and survival rate analyses.

\section{Data analysis}

All data were analyzed by analysis of variance (ANOVA) of the results obtained at the different temperature treatments using a General Linear Model (GLM) procedure in SAS (SAS Institute, 1996). Means were compared using the least significant difference (LSD) test. A linear regression analysis was used to estimate the lower developmental threshold for the nymphal stages by using the developmental rate data obtained at constant temperatures from 15 to $22^{\circ} \mathrm{C}$. Developmental rates obtained at temperatures higher than $22^{\circ} \mathrm{C}$ were outside the linear segment of the growth curve and not, therefore, included in the linear regression. The lower developmental threshold was the X-intercept of the linear equation (Maelzer, 1977; Wang \&Tsai, 2000)

\section{RESULTS}

\section{Development of nymphs}

Developmental times for total nymphal development at four constant temperatures are presented in Table 1 . The shortest developmental time (5.89 d) was recorded at $22^{\circ} \mathrm{C}$ and was 3.44 and 1.05 days shorter than at $18^{\circ} \mathrm{C}$ and $25^{\circ} \mathrm{C}$ respectively. Clearly at $22^{\circ} \mathrm{C}$ the rate of nymphal development $(0.17)$ was higher than at any other temperature. The longest developmental time (12.33 days) was recorded at $15^{\circ} \mathrm{C}$. The developmental rate was lower at $25^{\circ} \mathrm{C}$ than at $22^{\circ} \mathrm{C}$. The nymphal developmental times at different temperatures were significantly different from one another $(P<0.01)$ (Table 1$)$. Consistent with this, the developmental rates at the different temperatures differed significantly $(P<0.01)$ (Table 1$)$.

The generation time is a function of nymphal development time. In this study the generation time was longest and shortest at $15^{\circ} \mathrm{C}$ and $22^{\circ} \mathrm{C}$ respectively (Table 1 ).

A linear regression was fitted to the developmental rate vs. temperature data, resulting in the following equation and $\mathrm{R}^{2}$ values: $y=0.0129 x-0.1167, R^{2}=0.9771$ (Fig. 1). The temperature point at which this regression intercepts the $\mathrm{X}$-axis (i.e. zero developmental rate) was taken as the lower developmental threshold (Maelzer, 1977). This was calculated (by extrapolation below $22^{\circ} \mathrm{C}$ ) and found to be $9.05^{\circ} \mathrm{C}$. After determination of the lower developmental threshold, the number of degreedays required for development was calculated. Based on this, the degree-day requirement was found to be $77.5 \mathrm{dd}$, which is the period a first nymphal instar of M. rosae needs to become an adult.

\section{Longevity of adult females and reproduction}

The effect of temperature on fecundity and female longevity are presented in Table 2 . The pre-reproductive delay decreased markedly with increase in temperature from $15^{\circ} \mathrm{C}$ to $22^{\circ} \mathrm{C}$. However, there was no significant difference in the prereproductive delay at $22^{\circ} \mathrm{C}$ and $25^{\circ} \mathrm{C}$. The longest lifespan of apterous females $(12.38 \mathrm{~d})$ was observed at $15^{\circ} \mathrm{C}$ and the shortest $(8.06 \mathrm{~d})$ at $25^{\circ} \mathrm{C}$. The longevity of females at $25^{\circ} \mathrm{C}$ was significantly different from that at the other temperatures (Table $2 ; P<0.01)$. The mean adult longevity declined with increase in

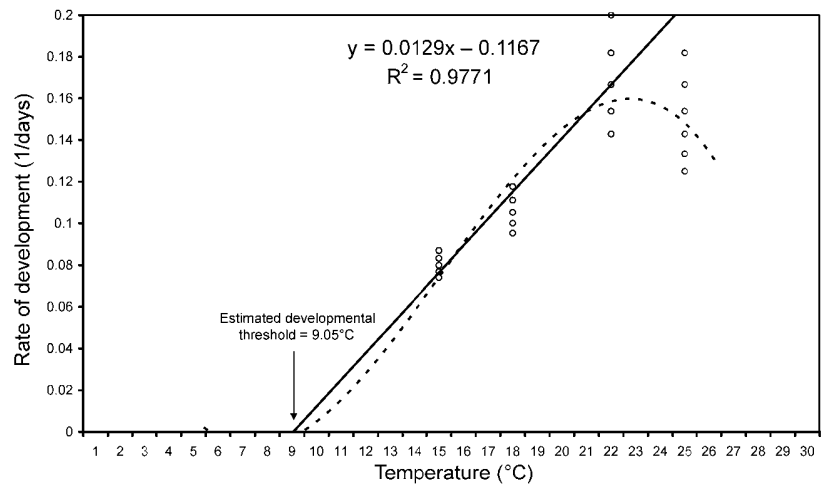

Fig. 1. Rate of development (day $\left.{ }^{-1}\right)$ of nymphal stage of $M$. rosae as a function of temperature $\left({ }^{\circ} \mathrm{C}\right)$. ANOVA: $\mathrm{F}=197.74$, $\mathrm{df}=26, \mathrm{p}<0.001$. Solid line shows the linear regression of temperature range $15-22^{\circ} \mathrm{C}$. The dotted line is a diagrammatic representation of a speculative higher order regression. 
TABLE 2. Mean \pm SE pre-reproduction delay, female longevity, fecundity and intrinsic rate of increase of $M$. rosae at four constant temperatures. Means in columns with different letters are significantly different from one another $(P<0.01$, GLM) in ANOVA (LSD).

\begin{tabular}{ccccc}
\hline Temperature $\left({ }^{\circ} \mathrm{C}\right)$ & Pre-reproductive delay (Days) & Female longevity (Days) & No. progeny per female & Intrinsic rate of increase $\left(\mathrm{r}_{\mathrm{m}}\right)$ \\
\hline 15 & $3.55 \pm 0.17 \mathrm{a}$ & $12.38 \pm 0.18 \mathrm{a}$ & $11.38 \pm 0.53 \mathrm{a}$ & 0.113 \\
18 & $2.61 \pm 0.16 \mathrm{~b}$ & $11.11 \pm 0.26 \mathrm{a}$ & $17.67 \pm 0.71 \mathrm{~b}$ & 0.178 \\
22 & $1.39 \pm 0.14 \mathrm{c}$ & $11.08 \pm 0.39 \mathrm{a}$ & $28.88 \pm 0.90 \mathrm{c}$ & 0.311 \\
25 & $1.81 \pm 0.09 \mathrm{c}$ & $8.06 \pm 0.37 \mathrm{~b}$ & $8.38 \pm 0.37 \mathrm{~d}$ & 0.180 \\
\hline
\end{tabular}

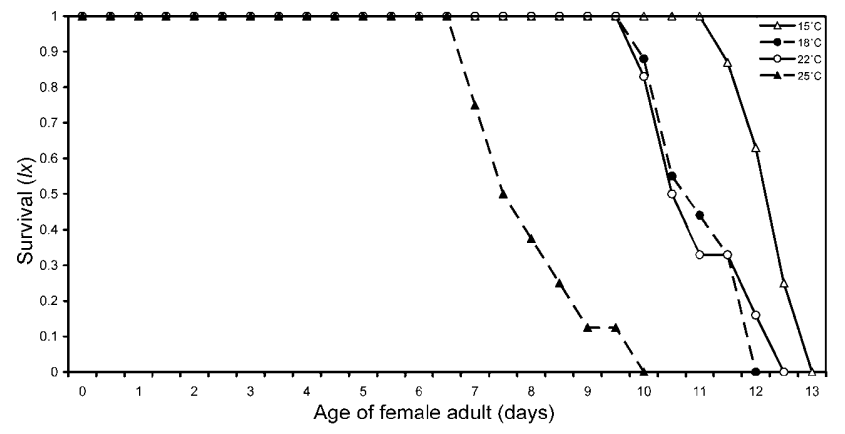

Fig. 2. Survival rates of apterous females of M. rosae at different temperatures.

temperature from $15^{\circ} \mathrm{C}$ to $25^{\circ} \mathrm{C}$; therefore mean adult longevity is negatively correlated with temperature.

As in other aphid species the survival rate $(l x)$ of $M$. rosae changes in response to temperature (Fig. 2). No mortality of apterous adults occurred before $7 \mathrm{~d}$ at any of the temperatures.

Temperature also influenced fecundity (Table 2), which ranged from 8.38 to 28.88 (progeny/female). It increased from 11.38 to 28.88 with increase in temperature from $15^{\circ} \mathrm{C}$ to $22^{\circ} \mathrm{C}$ and decreased at temperatures higher than $22^{\circ} \mathrm{C}$. The intrinsic rate of increase was greatest $(0.311)$ and smallest $(0.113)$ at $22^{\circ} \mathrm{C}$ and $15^{\circ} \mathrm{C}$, respectively (Table 2 ).

\section{DISCUSSION}

The development of M. rosae, like any other poikilothermic species, occurs within a certain range of temperatures. The developmental rate curve (Fig. 1) shows three significant features. First, the middle section is approximately a straight line, within this temperature range the rate of development is directly proportional to temperature. This is the optimal range. Second, the descending section of the curve shows that development is slowing down, this slowing down is related to increase in temperature. If the temperature is increased further, the aphid succumbs, indicating that the upper developmental temperature has been reached. Like other insects, aphids also develop more slowly at higher temperatures when approaching the upper developmental threshold. At temperatures above $22^{\circ} \mathrm{C}$, temperature has a negative effect on rose aphid development so that the developmental rate declines causing the developmental rate to be non-linear. This might be due to various reasons. One is that high temperature affects the aphids physiology unfavourably.

The third fact concerning the developmental curve is that the curve intersects the abscissa, at this intersection, the rate of development is zero (Pfadt, 1971). The terms lower and upper developmental threshold are used to indicate that the development ceases below the former and above the latter (Dixon, 1987; Wang \& Tsai, 2000). The developmental rate of aphids within the range between the lower and upper threshold tem- peratures is usually linear (Dixon, 1987). Our results, in accordance with those obtained by others (i.e. Wang \& Tsai, 2000; Collins \& Leather, 2001; Satar \& Yokomi, 2002) indicate that the relationship between the development and temperature is non linear at the extremes of an aphid's physiological tolerance.

Some aphid species (such as M. rosae) have a limited range of host plants, food quality and temperature over which their population increases (Dixon, 1998). Our study indicates that the developmental rate of $M$. rosae declines at temperatures higher than $22^{\circ} \mathrm{C}$. This is similar to the previous reports by Olmez et al. (2003) and Maelzer (1977) who suggested that the developmental rate of $M$. rosae was retarded at temperatures above $22.5^{\circ} \mathrm{C}$. In this study, based on four temperatures, all of the parameters of $M$. rosae life history were optimum at $22^{\circ} \mathrm{C}$. Accepting that the optimum temperature for M. rosae is $22^{\circ} \mathrm{C}$ the reproduction and nymphal developmental time are at their maximum and minimum at this temperature, respectively. Furthermore, at this temperature the intrinsic rate of increase was higher (0.311) than at the other temperatures used. A similar trend was also observed for the rose aphid by Olmez et al. (2003) who report that $22.5^{\circ} \mathrm{C}$ is the optimum temperature for M. rosae, because the survival, female longevity and intrinsic rate of increase $(0.170865)$ are highest at this temperature. Similarly, Maelzer (1977) calculated the $\mathrm{r}_{\mathrm{m}}$ for M. rosae to be 0.334 at $20.05^{\circ} \mathrm{C}$ under field conditions in Australia.

Intrinsic rate of increase is often used to measure the influence of various environmental factors on the population growth of aphids (quoted from Tang et al., 1999). Our study of the population dynamics of $M$. rosae in the field corroborate the results presented here. In Iran, the population of rose aphids starts to increase from early February onwards, coinciding with the gradual increase in average daily temperature above $10^{\circ} \mathrm{C}$. In early May, the population increase of the rose aphid gains speed due to the high nutritional quality of the host plant and an average temperature of about $22^{\circ} \mathrm{C}$. But, from late June onward the average temperature exceeds $25^{\circ} \mathrm{C}$ and the aphid population decreases. Once more, in early October, when the temperature falls to about $20^{\circ} \mathrm{C}$, the rose aphid population starts to increase again.

The negative effect of high temperatures on aphids has also been recorded in other papers. For example, $25^{\circ} \mathrm{C}$ had a detrimental effect on the development and survival of immature stages of M. rosae (Olmez et al., 2003). Temperatures higher than $32^{\circ} \mathrm{C}$ caused a decrease in developmental rate of Aphis spiraecola (Wang \& Tsai, 2000). Similarly, nymphal developmental rate of Brachycaudus schwartzi decreased at temperatures higher than $25^{\circ} \mathrm{C}$ and mortality of nymphs was $100 \%$ at $35^{\circ} \mathrm{C}$ (Satar \& Yokomi, 2002). However, in other aphid species, an increase in temperature had a positive effect on the developmental rate and they thrive at warmer temperatures. The pre-reproductive and developmental time of rose grain aphid, Metopolophium dirhodum, decrease with increase in temperature from 10 to $25^{\circ} \mathrm{C}$ (Zhou \& Carter, 1992). The developmental time of the immature stages of Aphis gossypii decreased from 
12.0 days at $15^{\circ} \mathrm{C}$ to 4.5 days at $30^{\circ} \mathrm{C}$; this species has an upper developmental threshold at $32-35^{\circ} \mathrm{C}$ (Kersting et al., 1999).

Our data indicate that the minimum pre-reproductive delay (1.389) and maximum progeny per female (28.875) occur at $22^{\circ} \mathrm{C}$. These results are similar to those obtained by Olmez et al. (2003). They report that the shortest pre-reproductive period (1.42) and the largest number of progeny per female (34.92) were recorded at $22.5^{\circ} \mathrm{C}$. The fecundity of $M$. rosae varied with temperature while in other aphids, such as Metopolophium dirhodum, the total number of nymphs produced per apterous adult was not affected by temperature between $10-25^{\circ} \mathrm{C}$ (Zhou \& Carter, 1992). In different aphid species the optimum temperature for reproduction is not the same. For example, the optimum temperature for the growth and fecundity of Rhopalosiphum maidis is $25^{\circ} \mathrm{C}$ (Wang et al., 2002) whereas in the turnip aphid, Lipaphis erysimi, the optimum reproductive temperature is $19.28^{\circ} \mathrm{C}$ (Zhao et al., 1990). On the other hand, the mean number of nymphs produced by Rhopalosiphum rufiabdominalis is maximum (63.32) at $20^{\circ} \mathrm{C}$ (Tsai et al., 1998).

Macrosiphum rosae required $77.5 \mathrm{dd}$ for development from the 1st instar to adult, with a lower developmental threshold of $9.05^{\circ} \mathrm{C}$. The estimated developmental threshold is similar to that reported by Maelzer $(1977)\left(10.1^{\circ} \mathrm{C}\right)$, who also estimates 57.2 $\mathrm{dd}$ are needed for the development of apterous females, which is 20.3 dd less than our estimate. This difference appears to be mainly due to the difference in the lower developmental thresholds. Our results indicate that rose aphid populations in Iran can develop at lower temperatures than those in Australia. Furthermore, our study confirms that geographically separated populations of aphids can significantly differ in terms of the effect of temperature on development and population growth rates (Tang et al., 1999). Such differences may arise from local adaptation under conditions of geographical separation. Local adaptation is a genetic change in a population in response to a geographically localized selection pressure. Local adaptation occurs when selective pressures vary across the landscape. Important factors could include differences in temperature, host plant or even host plant genotype, elevation, soil type, light intensity, soil biota, herbivory etc. Local adaptation is a property of the population as a whole. Assuming that this adaptation has a genetic basis, it measures the association between spatial variability of the environment and the distribution of adaptive genetic variation (Gandon \& Michalakis, 2002). A variable environmental adaptation can be influenced by both the strength of selection and the evolutionary potential (Gandon \& Michalakis, 2002). The present research and the reports by Olmez et al. (2003) and Maelzer (1977) indicate that aphid populations from geographically separated areas respond to temperature differently. Alternatively, differences in biological parameters among separate aphid populations may be an indicator of genetic drift (Tang et al., 1999).

ACKNOWLEDGMENTS. Special thanks are expressed to N. Mahdavi for her assistance. We gratefully thank R. Zaree, J. Khajehali and M. Soleimani for their valuable cooperation in this study, and C.M. Collins, and an other anonymous reviewer and I. Hodek, the editor for their constructive comments on this manuscript.

\section{REFERENCES}

Alford D.V. 1991: A Colour Atlas of Pests of Ornamental Trees, Shrubs and Flowers. Wolfe Publ., London, 448 pp.

Blackman R.L. \& Eastop V.F. 2000: Aphids on the World's Crops: An Identification and Information Guide. 2nd ed. John Wiley \& Sons, Chichester, 466 pp.
Collins C.M. \& Leather S.R. 2001: Effect of temperature on fecundity and development of the Giant Willow Aphid, Tuberolachnus salignus (Sternorrhyncha: Aphididae). Eur. J. Entomol. 98: 177-182.

Dixon A.F.G. 1987: Parthenogenetic reproduction and the rate of increase in aphids. In Minks A.K. \& Harrewijn P. (eds): Aphids Their Biology, Natural Enemies and Control. Vol. A. Elsevier, Amsterdam, pp. 269-287.

Dixon A.F.G. 1998: Aphid Ecology, An Optimisation Approach. 2nd ed. Chapman \& Hall, Glasgow and London, $300 \mathrm{pp}$.

Gandon S. \& Michalakis Y. 2002: Local adaptation, evolutionary potential and host-parasite coevolution: interactions between migration, mutation, population size and generation time. J. Evol. Biol. 15: 451-462.

HeIE O.E. 1994: The Aphidoidea (Hemiptera) of Fennoscandia and Denmark. V. Family Aphididae: Part 2 of tribe Macrosiphini of subfamily Aphidinae. Fauna Entomol. Scand. 28: $242 \mathrm{pp}$.

JASKIEWICZ B. 1997: Observation on the occurrence of the rose aphid (Macrosiphum rosae L.) on bushes of Rosa rugosa Thunb. and R. canina L. Folia Hort. 9: 25-31.

Kersting U., Satar S. \& Uygun N. 1999: Effect of temperature on development rate and fecundity of apterous Aphis gossypii Glover (Hom., Aphididae) reared on Gossypium hirsutum L. J. Appl. Entomol. 123: 23-27.

MaELzER D.A. 1977: The biology and main causes of changes in numbers of the Rose Aphid, Macrosiphum rosae (L.), on cultivated roses in South Australia. Aust. J. Zool. 25: 269-284.

Morgan D., Walters K.F.A. \& Aegerter J.N. 2001: Effect of temperature and cultivar on pea aphid, Acyrthosiphon pisum (Hemiptera: Aphididae) life history. Bull. Entomol. Res. 91: 47-52.

Olmez S., Bayhan E. \& Ulusoy M.R. 2003: Effect of different temperatures on the biological parameters of Macrosiphum rosae (L.) (Homoptera: Aphididae). J. Plant Dis. Protect. 110: 203-208.

Pfadt R.E. 1971: Fundamentals of Applied Entomology. Mac Millan, New York, 692 pp.

SAS InSTITUTE 1996: SAS language and procedures, syntax, version 6.12, SAS Institute, Cary, NC, USA.

Satar S. \& Yокомi R. 2002: Effect of temperature and host on development of Brachycaudus schwartzi (Homoptera: Aphididae). Ann. Entomol. Soc. Am. 95: 597-602.

Tang Y.Q., Lapointe S.L., Brown L.G. \& Hunter W.B. 1999: Effects of host plant and temperature on the biology of Toxoptera citricida (Homoptera: Aphididae). Environ. Entomol. 28: 895-900.

Tsai J.H., LiU Y.H. \& LiU Y.H. 1998: Effect of temperature on development, survivorship, and reproduction of rice root aphid (Homoptera: Aphididae). Environ. Entomol. 27: 662-666.

WANG J.J. \& TsaI J.H. 2000: Effect of temperature on the biology of Aphis spiraecola (Homoptera: Aphididae). Ann. Entomol. Soc. Am. 93: 874-883.

WANG Y.H., Su L. \& WU J.X. 2002: Effect of temperature on the population increase of corn leaf aphid, Rhopalosiphum maidis. Entomol. Knowl. 39: 277-280.

Wyatt I.J. \& White P.F. 1977: Simple estimation of intrinsic increase rates for aphids and tetranychid mites. J. Appl. Ecol. 14: 757-766.

ZhaO H.Y., Wang S.Z. \& Zhang W.J. 1990: Effects of temperature on reproductive characteristics of turnip aphid. Insect Knowl. 27: 339-342.

ZHOU X. \& CARTER N. 1992: Effects of temperature, feeding position and crop growth stage on the population dynamics of the rose grain aphid, Metopolophium dirhodum (Hemiptera: Aphididae). Ann. Appl. Biol. 121: 27-37.

Received November 7, 2006; revised and accepted March 6, 2007 